\title{
Break-even analysis and size optimization of a PV/wind hybrid energy conversion system with battery storage - A case study
}

\author{
Orhan Ekren $^{\mathrm{a}}$, Banu Y. Ekren ${ }^{\mathrm{b}, *}$, Baris Ozerdem ${ }^{\mathrm{c}}$ \\ a Department of HVAC, Ege Vocational Training School, Ege University, Bornova, Izmir 35100, Turkey \\ ${ }^{\mathrm{b}}$ Industrial Engineering Department, Pamukkale University, Kinikli, Denizli 20070, Turkey

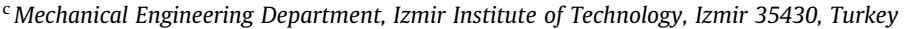

\section{A R T I C L E I N F O}

\section{Article history:}

Received 2 April 2008

Received in revised form 28 September

2008

Accepted 30 September 2008

Available online 8 November 2008

\section{Keywords:}

Hybrid energy

Break-even analysis

Optimization

Simulation

Response surface methodology

\begin{abstract}
A B S T R A C T
This paper aims to show an optimum sizing procedure of autonomous PV/wind hybrid energy system with battery storage and a break-even analysis of this system and extension of transmission line. We use net present value (NPV) method for the comparison of autonomous hybrid energy system and extension of transmission line cases. The case study is completed for the satisfaction of the electricity consumption of global system for mobile communication base station (GSM) at Izmir Institute of Technology Campus Area, Urla, Izmir, Turkey. First, we optimize the PV/wind energy system using response surface methodology (RSM) which is a collection of statistical and mathematical methods relying on optimization of response surface with design parameters. As a result of RSM, the optimum PV area, wind turbine rotor swept area, and battery capacity are obtained as $3.95 \mathrm{~m}^{2}, 29.4 \mathrm{~m}^{2}, 31.92 \mathrm{~kW} \mathrm{~h}$, respectively. These results led to $\$ 37,033.9$ hybrid energy system cost. Second, break-even analysis is done to be able to decide the optimum distance where the hybrid energy system is more economical than the extension of the transmission line. The result shows that, if the distance between national electricity network and the GSM base station location where the hybrid energy system is assumed to be installed is at a distance more than $4817 \mathrm{~m}$, the installation of hybrid energy system is more economical than the electricity network.
\end{abstract}

(c) 2008 Elsevier Ltd. All rights reserved.

\section{Introduction}

The rapid depletion of fossil fuel resources on a worldwide basis has necessitated an urgent search for alternative energy sources to meet to the present day demands. Alternative energy resources, such as solar and wind energies, are clean, inexhaustible, and environment-friendly potential resources of renewable energy options. It is prudent that neither a standalone solar nor a wind energy system can provide a continuous supply of energy due to seasonal and periodical variations. Therefore, in order to satisfy the load demand, hybrid energy systems are implemented that combine solar and wind energy conversion units with battery storage. A great deal of research [1-11] has been carried out on hybrid energy systems with respect to performance and optimization, and other related parameters of significance.

A schematic diagram of a basic hybrid energy system is given in Fig. 1. As seen in the figure, the electricity produced via PV array and wind turbine is regulated by voltage regulator components and the excess electricity produced by the hybrid system is stored by the battery banks to be used for later lacking loads. Here, the

\footnotetext{
* Corresponding author. Tel.: +90 258295 3132; fax: +90 2582953262 .

E-mail address: byekren@pamukkale.edu.tr (B.Y. Ekren).
}

amount of the electricity produced via the wind and the solar energy depends on the total solar radiation on horizontal surface and the wind speed in general.

In a typical hybrid energy system, one energy resource is at a lower supply level while the other one is usually at a higher supply level. For instance, in the winter seasons (in the Northern hemisphere), the wind speed is generally at its high level while the solar radiation is at its low level. In addition during the nights, solar energy cannot be utilized while the wind energy may be utilized efficiently. Hence, simultaneous utilization of multiple energy resources greatly enhances the certainty of meeting load demands. Therefore, it is critical to determine the levels of the energy resources at which the response reaches its optimum. The optimum design parameters depend on the objective function which could be either a minimum or a maximum. In this study, the main objective is chosen as the minimization of the cost of the PV/wind hybrid energy system as a function PV size, wind turbine rotor swept area and battery capacity.

\section{Background and motivation}

Recently, several research groups have carried out optimization of autonomous hybrid energy systems. Borowy and Salameh [1] 


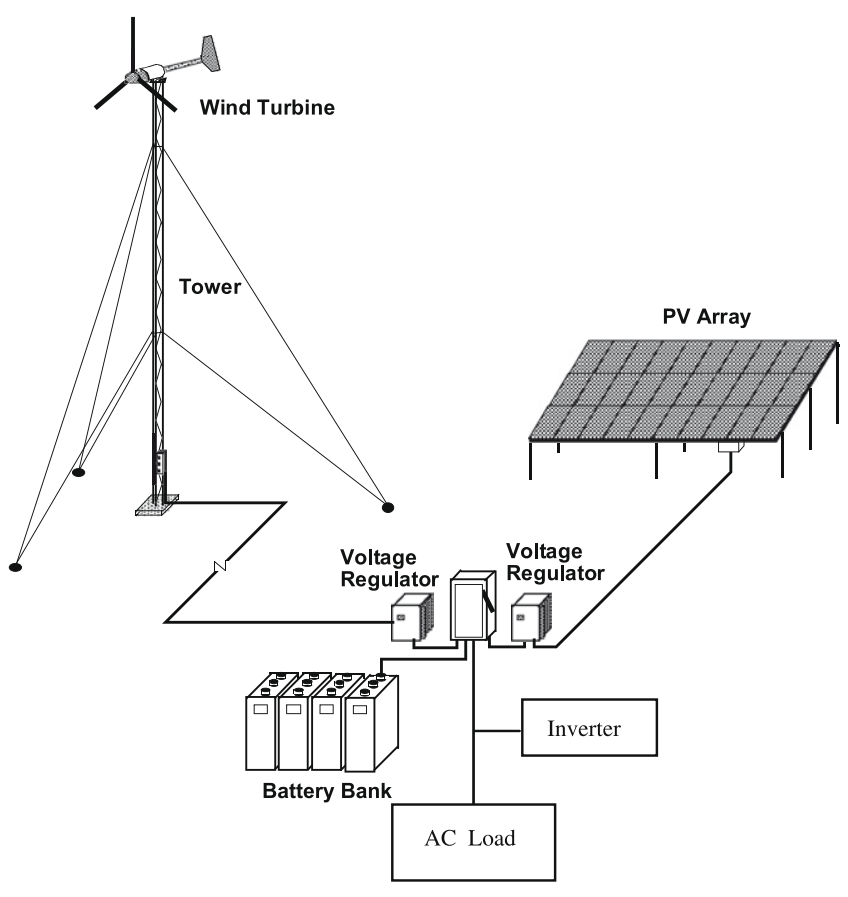

Fig. 1. Schematic diagram of a basic hybrid energy system.

have developed an algorithm to optimize a photovoltaic-array with battery bank for a standalone hybrid PV/wind system. The model proposed was based on a long-term hourly solar irradiance and peak load demand data of the site chosen. The number of PV modules in the hybrid energy system was calculated in the same algorithm. However, direct cost of the PV/wind systems was not considered for optimizing the hybrid energy system. Later, Borowy and Salameh [2] optimized a similar system taking into account the cost of the PV modules and battery systems. A graphic construction technique to optimize the size of the PV/wind energy system was presented by Markvart [3] considering the monthly average solar and wind energy values. On the other hand, unlike the methods based on hourly, daily, and monthly average basis, a statistical approach for optimizing the size of PV arrays and the number of batteries for a standalone PV/wind hybrid system was presented by Bagul et al. [4]. They proposed a three-event probabilistic approach to overcome the limitations of the conventional two-event approach in matching the actual distribution of the energy generated by hybrid systems. Recently, Celik [5] has made a techno-economic analysis and optimization of a PV/wind hybrid energy system. Also a comparative study with a standalone solar and wind system for the same conditions of load, insulation and wind velocities has been conducted. Being fundamentally different, Morgan et al. [6] have studied the performance of battery units in an autonomous hybrid energy system at various temperatures by considering the state of voltage (SOV) instead of the state of charge (SOC). Their algorithm was able to predict the hybrid energy system performance at various battery temperatures. Yang et al. [7] have proposed an optimization technique following the loss of power supply probability (LPSP) model for a PV/wind hybrid system taking reliability of the system into account. They demonstrated the utility of their model through a case study of a hybrid unit for a telecommunication system.

Ashok [8] proposes a model based on different system components of a hybrid energy system and develops a general model to find an optimal combination of energy components for a typical rural community, minimizing the life cycle cost.

Photovoltaic solar and wind energy conversion systems have been widely used for electricity supply in isolated locations far from the distribution network. If such systems are designed well they can provide a reliable service and operate in an unattended manner for extended periods of time. However, they suffer from the fluctuating characteristics of available solar and wind energy sources, which must be addressed in the design stage. The degree of desired reliability from a solar and wind process so as to meet a particular load can be fulfilled by a combination of properly sized wind turbine, PV panel, storage unit and auxiliary energy. Because the storage unit and auxiliary energy are needed to provide high reliability and avoid gross over-design of the solar and wind system $[9,10]$ we propose in our system the use of battery storage and auxiliary energy.

Hybrid energy system studies in the past [4-8,11-14] have been based upon a particular design scenario with a certain set of design values yielding the optimum design solution only. Such an approach, although providing the optimum solution, unfortunately lacks the ability to provide a general understanding about how the total system cost changes with the size of design parameters. This study is the first time in the PV/wind hybrid energy systems field, introduces both an optimization and a break-even analysis procedure at the same time to characterize the system cost to be able to decide on the more beneficial project which are installing a hybrid energy system or extension of the transmission line. The case study is completed for the electricity consumption of the GSM base station at Izmir Institute of Technology Campus Area, Urla, Turkey. Unlike the previous studies, in this study stochastic input variables for the solar radiation, wind speed, and electricity consumption are used and the system is optimized using RSM. And also, with the help of the approach presented here, one can easily obtain not only the optimum parameter sizes leading to the minimum life cycle cost and also obtain the right decision of the cost-effective solution for the electricity supply, installation of the hybrid system or the extension of transmission line, in remote areas having a certain distance from national electricity network.

\section{Building response surface metamodels}

RSM consists of a group of mathematical and statistical techniques that can be used to define the relationships between the response and the independent variables. RSM defines the effect of the independent variables, alone or in combination, on the processes. In addition to analyzing the effects of the independent variables, this experimental methodology also generates a mathematical model called a metamodel. The graphical perspective of the mathematical model has led to the term RSM [15].

Metamodels are developed to obtain a better understanding of the nature of the true relationship between the input variables and the output variables of the system under study. This approximate formula could be used as a proxy for the full-blown simulation itself in order to get at least a rough idea of what would happen for a large number of input-parameter combinations. A number of mathematical functions have been used to develop these metamodels [16-18].

Fig. 2 illustrates the general process of building response surface metamodels. The process typically involves taking observations in a starting region, usually according to an experimental design such as a factorial $\left(2^{k}\right)$ or fractional $\left(2^{k-p}\right)$. Here, $k$ is the number of factors and $1 / 2^{p}$ is called the degree of fractionation, because it represents the fraction of observations from a $2^{k}$ design that is required. For example, if a problem having 7 factors is studied, the necessary number of runs in the experiment would be $2^{7}=128$. Because each run may require time-consuming and costly setting and resetting of machinery, it is often not feasible to require many different production runs for the 


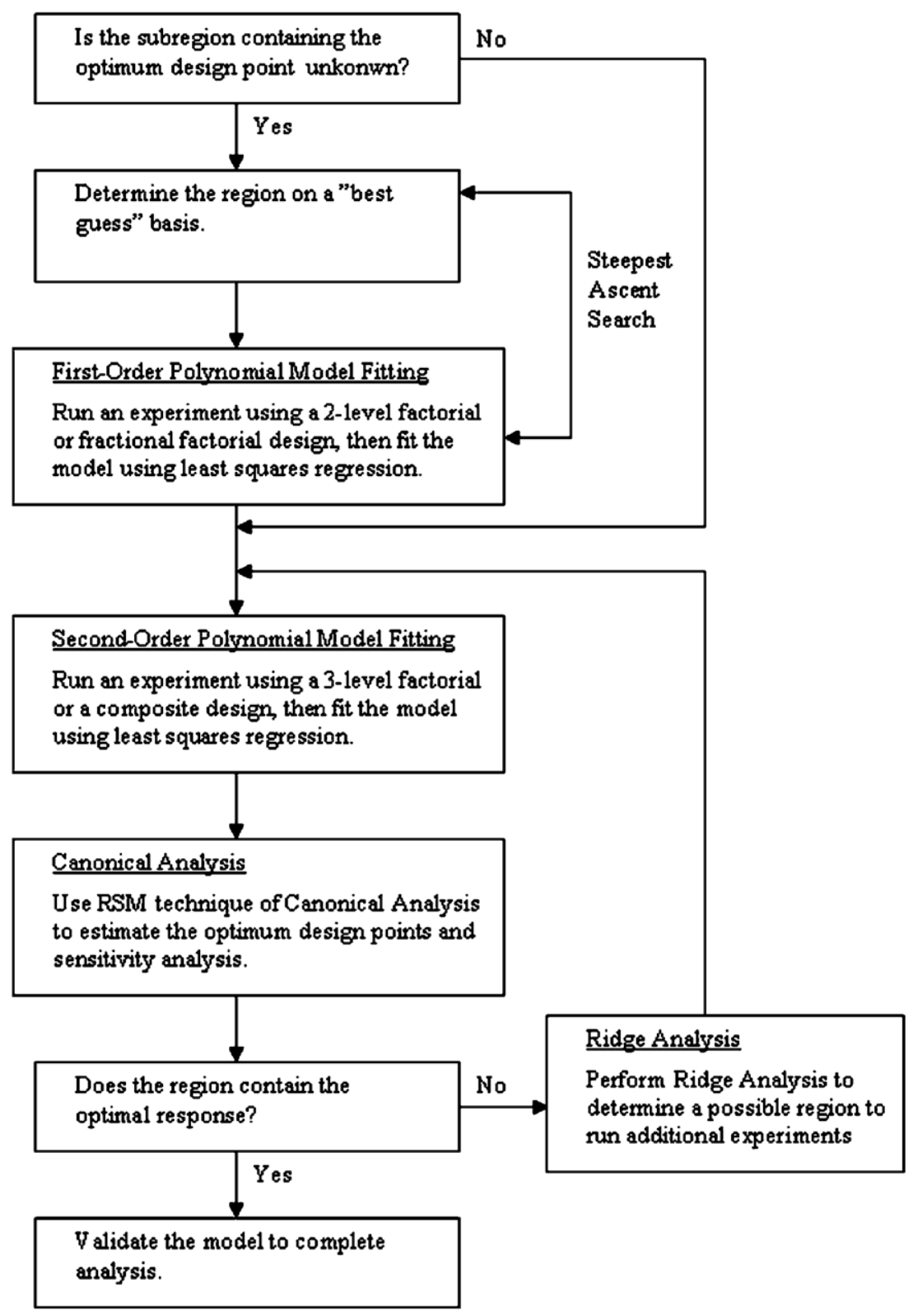

Fig. 2. Building response surface metamodels.

experiment. In these conditions, fractional factorials $\left(2^{k-p}\right)$ are used that "sacrifice" interaction effects so that main effects may still be computed correctly [15]. This exploratory phase is repeated until significant interaction effects exist. A significant interaction effect indicates that the response surface will be curved in that region, i.e. a second-order polynomial function. Provided that the experimenter has defined factor limits appropriately and/or taken advantage of all available tools in multiple regression analysis, then a higher-order model is generally unusual. Then, a three-level factorial or composite design is used to fit response surface to a second-order polynomial metamodel. At last, canonical analysis is employed to investigate the response surface in order to determine whether the estimated stationary point is a maximum, a minimum, or a saddle-point. In case, the estimated surface is determined not to have a simple optimum well within the range of experimentation, then ridge analysis is performed to aid in the interpretation of the existing response system $[19,20]$.
In this study, first of all, a factorial ANOVA analysis is conducted in statistical analysis software, SPSS 9.0, at 95\% confidence level so as to understand whether the main effects and interaction effects of the independent variables are significant [21]. Since a significant two-way interaction effect is observed at the end of the ANOVA analysis, a second-order response surface metamodel is built using a three-level factorial design. The metamodel represents the cost function as the output performance variable, and PV size, wind turbine rotor swept area and battery capacity as the input variables. Once the second-order metamodel is constructed, size optimization is accomplished in RSM.

The purpose of a simulation metamodel validation is to investigate whether the metamodel can adequately approximate the behavior of the input-output generated by the simulation program. The assessment of this adequacy is necessary [16,22]. Here, the validity of the metamodel is determined by examining the model-fit-diagnostics. A lack-of-fit test and F-test are used to ascertain whether the model adequately fits the data. A check of 
the distribution of the residuals leads to the determination of the validity of the model assumptions [23].

\section{PV/wind hybrid energy system simulation}

The hybrid system relies on solar and wind energies as the primary power resources, and it is backed up by the batteries (see Fig. 1). Batteries are used because of the stochastic characteristics of the system inputs. The basic stochastic input variables of the model are solar radiation, wind speed, and the electricity consumption of the GSM base station. Because the behaviors of these variables are non-deterministic data, probability distributions are specified in order to carry out random-input simulation. Random data are generated in the simulation software, ARENA 10.0 [24]. In this study, hourly data are used in the simulation model. Therefore, one of the hybrid system model assumptions is that the input variables do not change throughout an hour. This means that the solar radiation and the wind speed input values are constant e.g. from 1:00 pm to 2:00 pm. in any month in the simulation model. The length of each simulation run is considered as twenty years of the economical life which consists of 365 days/year, $24 \mathrm{~h} /$ day, in total $175,200 \mathrm{~h}$. For each run, five independent replications are completed. In the simulation model, since it is a popular and useful variance reduction technique to compare two or more alternative configurations, the common random numbers (CRN) variance reduction technique is used. And since a steady state analysis is needed to analyze a long time period non-terminating system, the warm-up period is decided as $12,000 \mathrm{~h}$ [15]. Hourly mean solar radiation and wind speed data for the period of 2001-2003 (26,280 data $=24 \mathrm{~h} * 365$ days $* 3$ years) are recorded at a meteorological station where the suggested hybrid energy system is to be established. Technical specifications of the meteorological station are given in Table 1 [25].

\subsection{Solar radiation}

Fig. 3 shows average measured hourly total solar radiation on horizontal surface, $H$, based on months in a year. Hourly total solar radiation on tilted surface, $I_{T}$, is calculated using $H$ and optimum tilted angle of the PV panel, $\beta$ is taken as $38^{\circ}[14]$.

Table 2 presents fitted hourly total solar radiation distributions, for example, for three months, in June, July, and August. Each solar radiation distribution is different at each hour of the month. This means that solar radiation may vary in accordance with its distribution at each hour of the months which is not known in advance. Here, the existences of the zero values are due to the sunset.

Arena simulation software uses nine different theoretical distributions to fit data to a theoretical distribution. These are, Exponential, Gamma, Lognormal, Normal, Triangular, Uniform, Weibull, Erlang, and Beta distributions. Each of the distribution has its own probabilistic characteristics in creating random variables in a stochastic model.

\subsection{Wind speed}

In order to measure wind speed and prevailing wind direction, a three-cup anemometer and a wind vane are used. Hourly average wind speeds at $10-\mathrm{m}$-height for all months of the year, can be seen

Table 1

Main characteristics of the meteorological station.

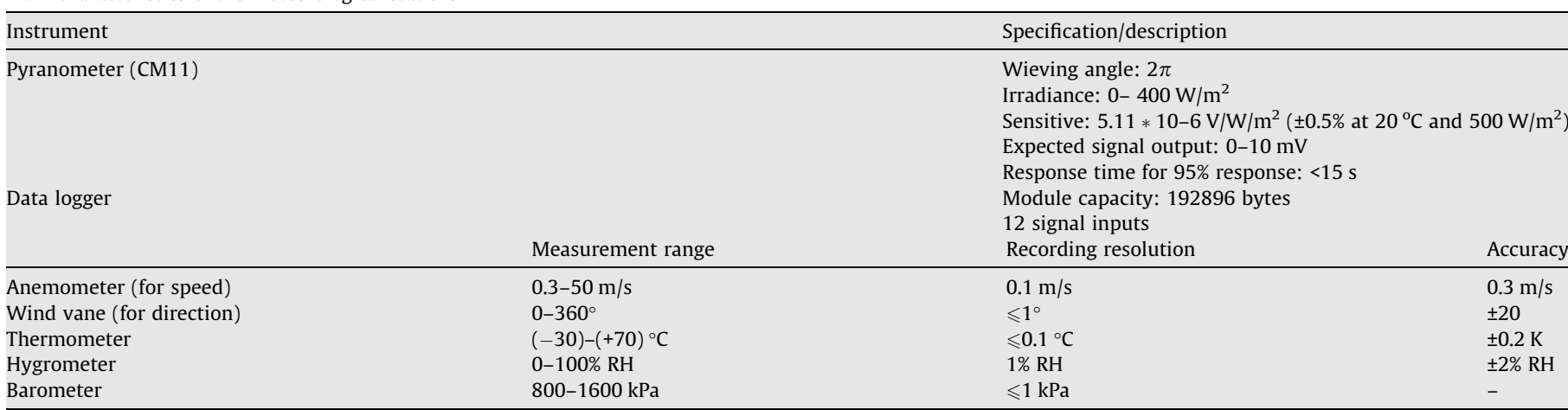

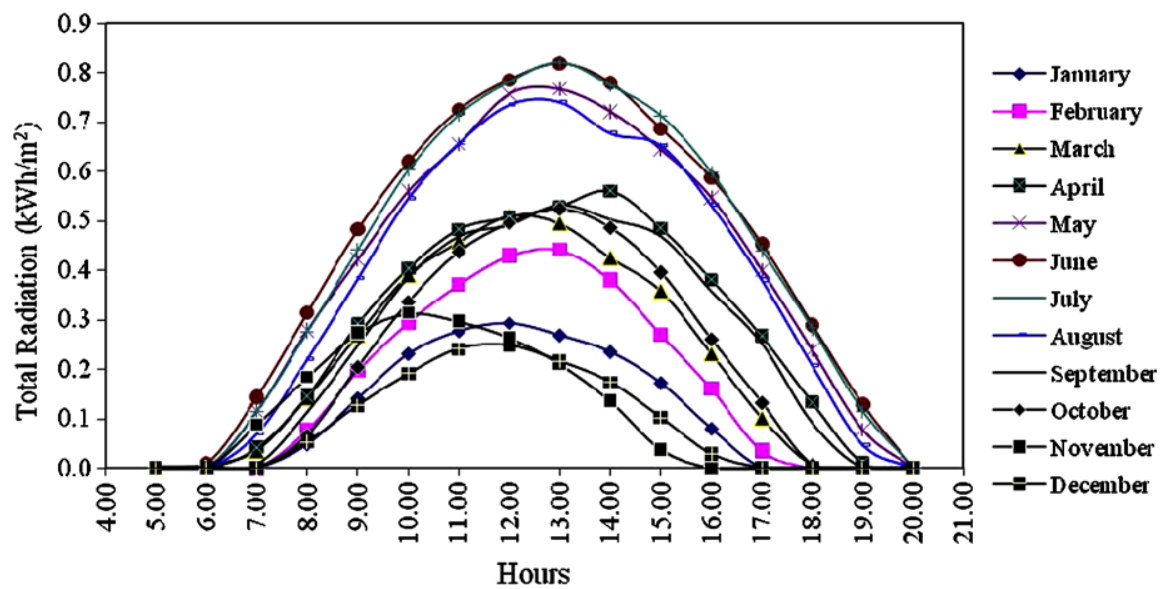

Fig. 3. Average hourly total solar radiation on horizontal surface (measured) 
Table 2

Hourly solar radiation on horizontal surface distributions for months June-August $\left(\mathrm{W} / \mathrm{m}^{2}\right)$.

\begin{tabular}{|c|c|c|c|}
\hline \multirow[t]{2}{*}{ Hours } & \multicolumn{3}{|l|}{ Months } \\
\hline & June & July & August \\
\hline 00:00-01:00 & 0 & 0 & 0 \\
\hline 01:00-02:00 & 0 & 0 & 0 \\
\hline 02:00-03:00 & 0 & 0 & 0 \\
\hline 03:00-04:00 & 0 & 0 & 0 \\
\hline 04:00-05:00 & 0 & 0 & 0 \\
\hline 05:00-06:00 & 0 & 0 & 0 \\
\hline 06:00-07:00 & $-0.001+37 * \operatorname{BETA}(0.0269,0.0857)$ & 0 & 0 \\
\hline 07:00-08:00 & $48+123 * \operatorname{BETA}(2.71,0.787)$ & $\operatorname{NORM}(113,12.9)$ & $18+80 * \operatorname{BETA}(2.22,1.22)$ \\
\hline 08:00-09:00 & $\operatorname{NORM}(313,16.6)$ & $\operatorname{TRIA}(240,278,305)$ & $80+189 * \operatorname{BETA}(3.49,1.22)$ \\
\hline 09:00-10:00 & $\operatorname{NORM}(482,19.9)$ & $270+209 * \operatorname{BETA}(3.26,0.724)$ & $183+246 * \operatorname{BETA}(1.57,0.542)$ \\
\hline 10:00-11:00 & $481+173 * \operatorname{BETA}(2.39,0.602)$ & $\operatorname{NORM}(602,17.2)$ & $\operatorname{NORM}(545,55.8)$ \\
\hline $11: 00-12: 00$ & $558+206 * \operatorname{BETA}(2.51,0.601)$ & $\operatorname{NORM}(714,28.1)$ & $265+457 * \operatorname{BETA}(2.76,0.465)$ \\
\hline $12: 00-13: 00$ & $538+297 * \operatorname{BETA}(1.34,0.431)$ & $517+337 * \operatorname{BETA}(3.95,1.11)$ & $221+617 * \operatorname{BETA}(3.05,0.62)$ \\
\hline $13: 00-14: 00$ & $472+399 * \operatorname{BETA}(1.5,0.42)$ & $672+187 * \operatorname{BETA}(3.27,0.858)$ & $145+704 * \operatorname{BETA}(2.09,0.385)$ \\
\hline $14: 00-15: 00$ & $229+617 * \operatorname{BETA}(1.13,0.313)$ & $400+436 * \operatorname{BETA}(1.32,0.415)$ & $144+655 * \operatorname{BETA}(0.978,0.366)$ \\
\hline $15: 00-16: 00$ & $359+411 * \operatorname{BETA}(1.02,0.402)$ & $453+311 * \operatorname{BETA}(0.931,0.405)$ & $334+393 * \operatorname{BETA}(1.45,0.507)$ \\
\hline $16: 00-17: 00$ & $198+450 * \operatorname{BETA}(1.09,0.303)$ & $174+481 * \operatorname{BETA}(1.34,0.407)$ & $193+464 * \operatorname{BETA}(2.78,1.04)$ \\
\hline $17: 00-18: 00$ & $178+326 * \operatorname{BETA}(1.28,0.418)$ & $46+452 * \operatorname{BETA}(1.16,0.347)$ & $76+371 * \operatorname{BETA}(1.47,0.483)$ \\
\hline 19:00-20:00 & $103+233 * \operatorname{BETA}(1.55,0.387)$ & $69+258 * \operatorname{BETA}(2.46,0.527)$ & $\operatorname{TRIA}(78,266,278)$ \\
\hline $20: 00-21: 00$ & $63+91 * \operatorname{BETA}(1.54,0.604)$ & $-0.001+148 * \operatorname{BETA}(3.43,1.02)$ & $-0.001+101 * \operatorname{BETA}(0.974,1.13)$ \\
\hline $22: 00-23: 00$ & 0 & 0 & 0 \\
\hline 23:00-00:00 & 0 & 0 & 0 \\
\hline
\end{tabular}

in Fig. 4. These average hourly measured solar radiation and wind speed data figures are given for a general idea of the energy potential of the area. In the simulation model we use long-term dynamic hourly data. This height is the universally standard meteorological measurement height [26]. Table 3 shows hourly wind speed distributions of three months as an example.

\subsection{Electricity consumption}

The third stochastic data is the electricity consumption of the GSM base station. The data are collected from a base station in Urla, Izmir for every hour of the day. In this study, the existence of a seasonal effect on the GSM base station's electricity consumption is ignored. The statistical data are collected in 15 random days in each season, fall, winter, spring, and summer. Hence, totally $15 * 4=60$ electricity consumption data are collected for an hour (e.g. for $1.00 \mathrm{pm}$ ). Then these data are fitted to theoretical distributions without considering seasonal effects. Fig. 5 illustrates the hourly mean electricity consumption values of the GSM base station. And the fitted distributions are given in Table 4 .

The output of the wind generator and PV panels are DC power and inverter converts it to the AC power.

\subsection{Formulations}

If the hybrid energy systems are well designed, they provide a reliable service for an extended period of time. The sizes of system components are decision variables, and their costs are objective function. Objective function here in is the cost of PV, wind turbine rotor, battery and also the battery charger, installation, maintenance, and engineering cost. A solar and wind hybrid energy system with the sizes of $a_{s}$ and $a_{w}$, respectively, can be defined as

$A_{s}=\eta \cdot A_{s}$

where $\eta$ is the PV module efficiency, $A_{s}$ is the PV array area and

$a_{w}=C_{p} \cdot\left(\pi \cdot r^{2}\right)$

where $C_{p}$ is the power coefficient, and $r$ is the rotor radius. Here, $\pi . r^{2}$ represents $A_{w}$, rotor swept area. $\eta$ value is taken as a variable value depending on PV module type and module temperature. In the study, mono-crystal silicon PV module type, rated output of $75 \mathrm{~W}$ at $1000 \mathrm{~W} / \mathrm{m}^{2}$ is used. Here, $\eta$ value changes between $7 \%$ and $17 \%$ based on module surface temperatures which are between $10^{\circ} \mathrm{C}$ and $70{ }^{\circ} \mathrm{C}[27,28]$. In the simulation model, for December, January and February the temperature and the $\eta$ values are assumed to be

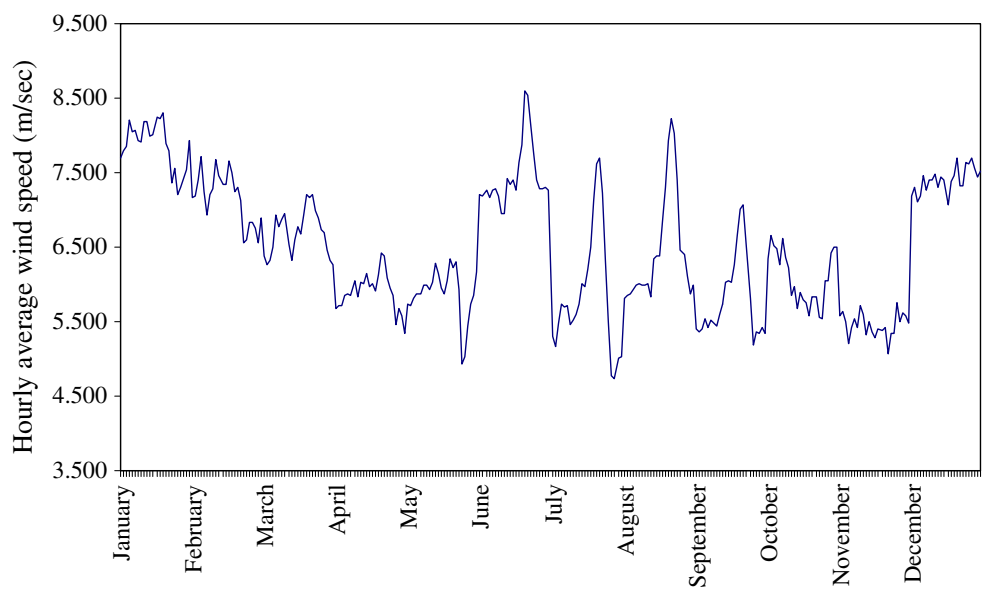

Fig. 4. Average hourly average wind speeds (measured). 
Table 3

Hourly average wind speed distributions for months, January-March (m/s).

\begin{tabular}{|c|c|c|c|}
\hline \multirow[t]{2}{*}{ Hours } & \multicolumn{3}{|l|}{ Months } \\
\hline & January & February & March \\
\hline $00: 00-01: 00$ & $\operatorname{TRIA}(2,3.08,18)$ & $2+13 * \operatorname{BETA}(1.07,1.57)$ & $1+12 * \operatorname{BETA}(1.46,1.79)$ \\
\hline 01:00-02:00 & $1+\operatorname{LOGN}(7.02,5.28)$ & WEIB $(7.75,1.88)$ & $1+11 * \operatorname{BETA}(1.54,1.66)$ \\
\hline 02:00-03:00 & $2+14 * \operatorname{BETA}(0.881,1.23)$ & $\operatorname{GAMM}(2.24,3.31)$ & $\operatorname{TRIA}(2,3.95,13)$ \\
\hline 03:00-04:00 & $\operatorname{NORM}(8.22,3.96)$ & $1+\operatorname{LOGN}(7.1,5.85)$ & TRIA $(1,4.52,14)$ \\
\hline 04:00-05:00 & $2+\operatorname{WEIB}(6.7,1.52)$ & $1+\operatorname{LOGN}(6.61,5.58)$ & $\operatorname{NORM}(6.93,2.66)$ \\
\hline 05:00-06:00 & $\operatorname{TRIA}(2,4.21,18)$ & $1+\operatorname{LOGN}(6.3,5.69)$ & $2+\operatorname{WEIB}(5.3,1.78)$ \\
\hline 06:00-07:00 & $1+15 * \operatorname{BETA}(1.37,1.6)$ & $2+\operatorname{WEIB}(5.5,1.2)$ & TRIA(1, 7.62, 12) \\
\hline 07:00-08:00 & $1+\operatorname{LOGN}(7.23,5.21)$ & $2+\operatorname{WEIB}(5.87,1.48)$ & $\operatorname{TRIA}(1,7,13)$ \\
\hline 08:00-09:00 & $2+\operatorname{WEIB}(6.84,1.66)$ & $2+17 * \operatorname{BETA}(1.14,2.28)$ & $\operatorname{TRIA}(1,7.69,10.9)$ \\
\hline 09:00-10:00 & $1+\operatorname{WEIB}(8.11,2.12)$ & $2+\operatorname{WEIB}(5.98,1.41)$ & $1+\operatorname{GAMM}(1.13,4.69)$ \\
\hline 10:00-11:00 & $2+\operatorname{WEIB}(6.71,1.8)$ & $1+\operatorname{WEIB}(7.1,1.61)$ & $2+\operatorname{WEIB}(5.15,2.25)$ \\
\hline $11: 00-12: 00$ & $2+\operatorname{WEIB}(6.78,1.87)$ & $1+\operatorname{ERLA}(2.11,3)$ & $\operatorname{NORM}(6.77,2.54)$ \\
\hline $12: 00-13: 00$ & $3+\operatorname{ERLA}(2.63,2)$ & $2+22 * \operatorname{BETA}(0.955,2.76)$ & $\operatorname{NORM}(6.68,2.81)$ \\
\hline $13: 00-14: 00$ & $2+\operatorname{GAMM}(2.45,2.54)$ & $1+\operatorname{WEIB}(7.24,1.56)$ & $1+\operatorname{ERLA}(1.98,3)$ \\
\hline $14: 00-15: 00$ & $2+\operatorname{WEIB}(6.97,1.58)$ & $1+\operatorname{WEIB}(6.92,1.57)$ & $1+\operatorname{WEIB}(6.97,1.76)$ \\
\hline $15: 00-16: 00$ & $2+\operatorname{WEIB}(6.54,1.6)$ & $1+\operatorname{WEIB}(7.06,1.61)$ & $\operatorname{NORM}(7.17,3.63)$ \\
\hline $16: 00-17: 00$ & $2+\operatorname{WEIB}(6.41,1.63)$ & $1+\operatorname{WEIB}(6.86,1.6)$ & $2+17 * \operatorname{BETA}(1.37,3.1)$ \\
\hline $17: 00-18: 00$ & $\operatorname{NORM}(7.35,3.12)$ & $1+\operatorname{ERLA}(2.8,2)$ & $\operatorname{NORM}(6.98,2.9)$ \\
\hline 19:00-20:00 & $\operatorname{TRIA}(2,4.7,16)$ & $\operatorname{NORM}(6.84,3.82)$ & $1+\operatorname{LOGN}(6.07,3.79)$ \\
\hline $20: 00-21: 00$ & $2+\operatorname{WEIB}(5.76,1.57)$ & $1+\operatorname{WEIB}(6.46,1.57)$ & $2+12 * \operatorname{BETA}(1.06,1.56)$ \\
\hline $22: 00-23: 00$ & $1+\operatorname{WEIB}(7.01,1.73)$ & $1+\operatorname{WEIB}(6.4,1.62)$ & $1+\operatorname{GAMM}(1.84,3.1)$ \\
\hline $23: 00-00: 00$ & $\operatorname{NORM}(7.41,4.06)$ & $1+\operatorname{WEIB}(6.4,1.62)$ & $\operatorname{TRIA}(2,4.39,13)$ \\
\hline
\end{tabular}

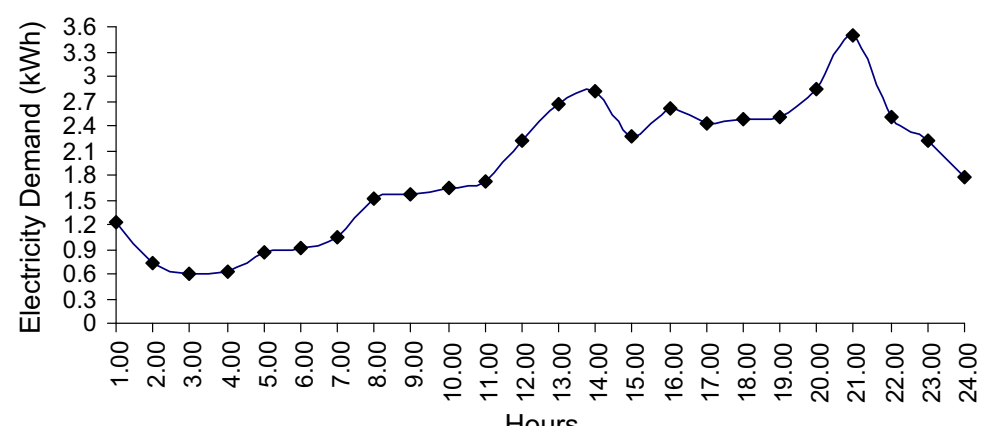

Hours

Fig. 5. Hourly average demand of GSM base station.

Table 4

Hourly electricity demands $(\mathrm{kW})$

\begin{tabular}{ll}
\hline Hours & Demands \\
\hline $00: 00-01: 00$ & $\operatorname{NORM}(1.21,0.602)$ \\
$01: 00-02: 00$ & $1.72 * \operatorname{BETA}(1.13,1.55)$ \\
$02: 00-03: 00$ & $\operatorname{WEIB}(0.645,1.28)$ \\
$03: 00-04: 00$ & $\operatorname{GAMM}(0.565,1.11)$ \\
$04: 00-05: 00$ & $\operatorname{EXPO}(0.854)$ \\
$05: 00-06: 00$ & $3.31 * \operatorname{BETA}(1.28,3.34)$ \\
$06: 00-07: 00$ & $2.86 * \operatorname{BETA}(1.15,1.96)$ \\
$07: 00-08: 00$ & $\operatorname{WEIB}(1.7,2.36)$ \\
$08: 00-09: 00$ & TRIA $(0,0.827,3.84)$ \\
$09: 00-10: 00$ & $3.84 * \operatorname{BETA}(2.46,3.25)$ \\
$10: 00-11: 00$ & $0.15+3.34 * \operatorname{BETA}(2.54,2.87)$ \\
$11: 00-12: 00$ & $0.28+\operatorname{LOGN}(1.91,0.951)$ \\
$12: 00-13: 00$ & $1+\operatorname{ERLA}(0.828,2)$ \\
$13: 00-14: 00$ & $1+\operatorname{LOGN}(1.82,1.43)$ \\
$14: 00-15: 00$ & $\operatorname{NORM}(2.27,0.626)$ \\
$15: 00-16: 00$ & $1+\operatorname{GAMM}(0.669,2.4)$ \\
$16: 00-17: 00$ & $1+\operatorname{GAMM}(0.417,3.45)$ \\
$17: 00-18: 00$ & $\operatorname{NORM}(2.47,0.685)$ \\
$19: 00-20: 00$ & $1+\operatorname{ERLA}(0.377,4)$ \\
$20: 00-21: 00$ & $1.11+\operatorname{ERLA}(0.436,4)$ \\
$22: 00-23: 00$ & $1.29+\operatorname{LOGN}(2.2,1.59)$ \\
$23: 00-00: 00$ & $1+\operatorname{GAMM}(0.435,3.48)$ \\
&
\end{tabular}

$10^{\circ} \mathrm{C}$ and $17 \%$, respectively. For March, April and May the temperature and the $\eta$ values are assumed to be $50{ }^{\circ} \mathrm{C}$ and $10 \%$, respec- tively. For June, July, August the temperature and the $\eta$ values are assumed to be $70{ }^{\circ} \mathrm{C}$ and $7 \%$, respectively. And, for SeptemberNovember the temperature and the $\eta$ values are assumed to be $30{ }^{\circ} \mathrm{C}$ and $13 \%$, respectively. These values are obtained from a manufacturer firm. $C p$ value is taken from a manufacturer firm as a graphic value which changes according to the wind speed value. Wind energy density, $W$, is calculated by Eq. (3):

$W=1 / 2 \cdot \rho \cdot V^{3} \cdot D$

$D$ is length of period. Because of hourly operating state, it is taken as $1 \mathrm{~h} . \rho$ is air density which is considered as 1.225 , and $V$ is hourly average wind velocity whose distribution is shown in Table 3.Solar radiation on tilted plate is calculated for isotropic sky assumption and using equation:

$I_{T}=I_{b} R_{B}+I_{d}(1+\cos \beta) / 2+\left(I_{b}+I_{d}\right)((1-\cos \beta) / 2$

$R_{b}=\cos \theta / \cos \theta z$

where, $I_{T}$ is total solar radiation on tilted surface, $I_{b}$ is horizontal beam radiation, $I_{d}$ is horizontal diffuse radiation, $R_{b}$ is ratio of beam radiation on tilt factor, $\theta$ is incidence angle, $\theta z$ is zenith angle, $\rho$ is surface reflectivity, $\beta$ is tilted angle of the plate.

The supply of hourly solar and wind energies must meet the hourly demand, $d$. This expression can be formulated as

$S \cdot a_{s}+W \cdot a_{w} \geq d$ 
where $S$ is the solar energy density on tilted surface, $H_{T}\left(\mathrm{~kW} \mathrm{~h} / \mathrm{m}^{2}\right)$ and $W$ is the wind energy density $\left(\mathrm{kW} \mathrm{h} / \mathrm{m}^{2}\right)$. If Eq. (5) is not realized, stored energy in the battery will be used. The battery is considered as full in the simulation initially and its efficiency is assumed as $85 \%$. The inverter's efficiency is considered $90 \%$ here. If the total of solar, wind, and battery energies still cannot meet the demand, the energy shortage will be supplied by an auxiliary energy source, whose unit cost, herein, is considered $\$ 0.5$ per $\mathrm{kW}$ h electricity. In this study, the location of the hybrid system is assumed in such a place where the unit cost of the auxiliary energy is more expensive than the electricity produced by the hybrid system. Therefore, the cost of extra energy here is decided such that it is three times as much of the average unit cost of the electricity produced by the hybrid system. Otherwise, if the unit cost of the auxiliary energy was less than that of the electricity produced by the hybrid system, the shortage could be supplied from the auxiliary energy source all the time without the need for such a hybrid system [5]. As seen in Eq. (6), the auxiliary energy cost is also a part of the total hybrid system cost. $C_{S}, C_{w}, C_{B}, C_{s h}$ and $C_{T}$ are the unit cost of photovoltaic, wind energy generator, battery, shortage electricity, and total hybrid energy system, respectively. $B_{C}$ denotes the battery capacity. $E_{i}$ is the total amount of the electricity energy shortage because of not meeting the demand during an hour $i$. $C_{s}$ are $\$ 5.8 / W_{p}$ (mono-crystal silicon, rated output of $75 \mathrm{~W}$ at $1000 \mathrm{~W} / \mathrm{m}^{2}$ ), $\$ 5.5 / W_{p}$ (multi-crystal silicon, rated output of $75 \mathrm{~W}$ at $1000 \mathrm{~W} / \mathrm{m}^{2}$ ) whereas $C_{w}$ is US $\$ 3 / W$ (rated output of $5000 \mathrm{~W}$ at $10 \mathrm{~m} / \mathrm{s}$ ), and $C_{B}$ is $\$ 180 / \mathrm{kW} \mathrm{h}$ (200 Ah $12 \mathrm{~V}$ lead acid battery) [14]. $C_{s h}$ is $\$ 0.5$ per $\mathrm{kWh}$ as explained above, and $n$ is the simulation time period, $175,200 \mathrm{~h}$. In this study, the inflation rate and time value of money are not considered.

$C_{T}=C_{s} \cdot a_{s}+C_{w} \cdot a_{w}+C_{B} \cdot B_{C}+\sum_{i=1}^{n} C_{s h} \cdot E_{i}$

In addition, a total of US $\$ 500$ battery charger cost, and $5 \%$ installation, maintenance and engineering cost of the initial hardware is also added into the total system cost for an assumed 20-yearlifetime.

\section{Experimental design and results}

Design of experiments is the design of all information-gathering exercises where variation is present, whether under the full control of the experimenter or not. Generally, the experimenter is interested in the effect of some process or treatment on some objects which are the experimental units.

Experimental design is widely used for understanding the effect of parameters in a system or a process so as to decrease the number of experiments, time, and material resources. Furthermore, the analysis performed on the results is easily realized, and experimental errors are minimized. Statistical methods measure the effects of change in operating variables and their mutual interactions on a system or a process through experimental design way [29].

In this study, a three-level, three-factorial Box-Behnken experimental design is used to evaluate the effects of selected independent variables on the responses to characterize the hybrid energy system and to optimize the procedure. This design is suitable for exploration of second-order (quadratic) response surfaces and for construction of second-order polynomial models, thus helping to optimize them by a small number of experimental runs [20]. Box-Behnken experimental design is an orthogonal design. Therefore, the factor levels are evenly spaced and coded for low, medium, and high settings, as $-1,0$ and $+1[19,30]$. For the threelevel, three-factorial Box-Behnken experimental design, a total of 15 experimental runs, shown in Table 5 , are needed. Here, $x_{1}, x_{2}$ and $x_{3}$ are the factors that could affect the cost function as given
Table 5

Coded values of factor levels for Box-Behnken design.

\begin{tabular}{llll}
\hline Experiment (run) & \multicolumn{2}{l}{ Factor and factor level } \\
\cline { 2 - 4 } & $x_{1}$ & $x_{2}$ & $x_{3}$ \\
\hline BB1 & -1 & -1 & 0 \\
BB2 & -1 & +1 & 0 \\
BB3 & +1 & -1 & 0 \\
BB4 & +1 & +1 & 0 \\
BB5 & -1 & 0 & -1 \\
BB6 & -1 & 0 & +1 \\
BB7 & +1 & 0 & -1 \\
BB8 & +1 & 0 & +1 \\
BB9 & 0 & -1 & -1 \\
BB10 & 0 & -1 & +1 \\
BB11 & 0 & +1 & -1 \\
BB12 & 0 & +1 & +1 \\
BB13 & 0 & 0 & 0 \\
BB14 & 0 & 0 & 0 \\
BB15 & 0 & 0 & 0 \\
\hline
\end{tabular}

in Eq. (6). $-1,0$ and +1 show the coded variables of these factor levels. -1 is the low level, 0 is the middle level and +1 is the high level of the factors. In the middle level, three independent replications, namely BB13, BB14, and BB15 in the table in this case, are needed.

In the design model, three factors are chosen as PV size, $A_{s}$, wind turbine rotor swept area, $A_{w}$, and the battery capacity, $B_{c}$. A list of factors and their levels is given in Table 6 . The levels are 0 and 10 , for -1 and +1 levels of PV size; 17 and 37 for -1 and +1 levels of wind turbine rotor swept area; and 10 and 50 for -1 and +1 levels of battery capacity. Since the amount of wind energy in this area is greater than the solar energy, the interval between the low and the high level of the wind turbine rotor swept area is greater than the interval of the low and the high level of the PV size. This means that, at the optimum point wind turbine rotor swept area tends to be greater than the PV size.

\subsection{Second-order polynomial (Quadratic) model fitting and RSM results}

The general representation of second order regression model of the design is shown in Eq. (7):

$$
\begin{aligned}
Y= & b_{0}+b_{1} x_{1}+b_{2} x_{2}+b_{3} x_{3}+b_{4} x_{1} x_{2}+b_{5} x_{2} x_{3}+b_{6} x_{1} x_{3}+b_{7} x_{1}^{2} \\
& +b_{8} x_{2}^{2}+b_{9} x_{3}^{2}
\end{aligned}
$$

where $Y$ is the selected response; $b_{0}-b_{9}$ are the regression coefficients and $x_{1}-x_{3}$ are the factors. This model is used to estimate the relationship between the cost function, $Y$, and the three independent factors, PV size, $x_{1}$, wind turbine rotor swept area, $x_{2}$, and battery capacity, $x_{3}$. Here, $b_{1}, b_{2}, b_{3}$ coefficients denote the main effect of factors $x_{1}, x_{2}$ and $x_{3}$, respectively. Besides, $b_{4}$ denotes the interaction between factors $x_{1}, x_{2} ; b_{5}$ denotes the interaction between factors $x_{2}, x_{3}$, and $b_{6}$ denotes the interaction between factors $x_{1}, x_{3}$. Finally, $b_{7}, b_{8}, b_{9}$ denote the quadratic effect of factors $x_{1}, x_{2}$ and $x_{3}$, respectively.

In order to fit the metamodel given in Eq. (7), 15 experiments with three independent replications in the middle are utilized as

Table 6

Factors and factor levels used in Box-Behnken experimental design.

\begin{tabular}{lccc}
\hline Factor & Level & & \\
\cline { 2 - 4 } & -1 & 0 & +1 \\
\hline$x_{1}:$ PV $\left(\mathrm{m}^{2}\right)$ & 0 & 5 & 10 \\
$x_{2}:$ wind $\left(\mathrm{m}^{2}\right)$ & 17 & 27 & 37 \\
$x_{3}: \mathrm{B}_{\mathrm{C}}(\mathrm{kW} \mathrm{h})$ & 10 & 30 & 50 \\
\hline
\end{tabular}


illustrated in Table 5 . The validity of the fitted model is tested by computing a lack-of-fit, $F$-test and residual analysis. For the metamodel fit and optimization procedure, a software called Design Expert 7.1 is used [30].

The results of the fitted standardized metamodel for the hybrid system is given in Eq. (8). The model is found to be significant at $95 \%$ confidence level by the $F$-test. In addition, the model does not exhibit lack-of-fit $(P>0.05)$. The lack-of-fit test measures the failure of the model to represent data in the experimental domain at points that are not included in the regression. If a model is significant, meaning that the model contains one or more important terms, and the model does not suffer from lack-of-fit, does not necessarily mean that the model is a good one. If the experimental environment is quite noisy or some important variables are left out of the experiment, then it is possible that the portion of the variability in the data not explained by the model, also called the residual, could be large. Thus, a measure of the model's overall performance referred to as the coefficient of determination and denoted by $R^{2}$ must be considered. The value $R^{2}$ quantifies goodness of fit. It is a fraction between 0.0 and 1.0, and has no units. Higher values indicate that the model fits the data better." added to the paper. At the same time, adjusted $R^{2}$ allowing for the degrees of freedom associated with the sums of the squares is also considered in the lack-of-fit test, which should be an approximate value of $R^{2}$.

$$
\begin{aligned}
\hat{Y}= & 38812.37-5008.24 x_{2}+2816 x_{1} x_{2}+10638.18 x_{2}^{2} \\
& +3393.62 x_{3}^{2}
\end{aligned}
$$

$R^{2}$ and adjusted $R^{2}$ are calculated as 0.984 and 0.956 , respectively. If adjusted $R^{2}$ is significantly lower than $R^{2}$, it normally means that one or more explanatory variables are missing. Here, the two $R^{2}$ values are not significantly different, and the normal probability plots of residuals do not show evidence of strong departures from normality as depicted in Fig. 6. Therefore, the overall second-order metamodel, as expressed in Eq. (8), for the response measure is significant and adequate.

In general, estimated standardized metamodel coefficients provide two types of information. The magnitude of a coefficient indicates how important that particular effect is and its sign indicates whether the factor has a positive or a negative effect on the response.

The estimated cost function, $\hat{Y}$, of the hybrid energy system obtained by RSM in Eq. (8), indicates that there is no main effect of PV size and battery capacity on the cost, while wind turbine rotor swept area, $x_{2}$, significantly affects the response variable

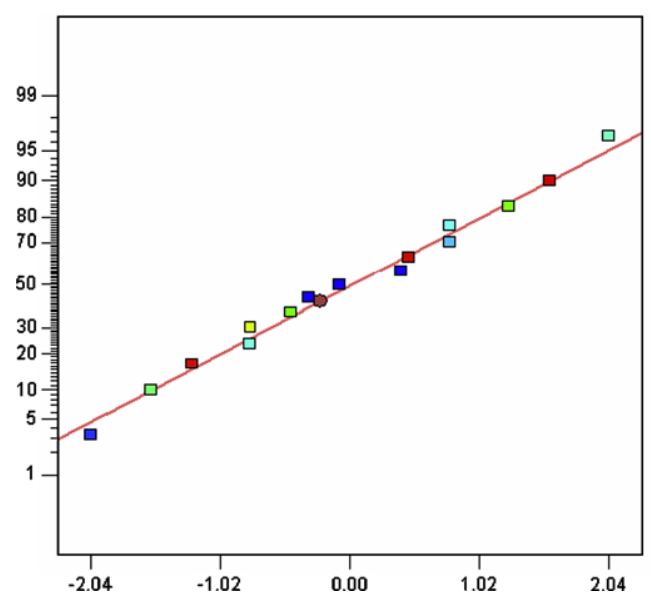

Fig. 6. Normal probability plot of residuals.



Fig. 7. Response surface of cost at fixed (optimum) battery capacity as a function of PV size, $x_{1}$, and wind turbine rotor swept area, $x_{2}$.

$(P<0.05)$. Instead of the main effect of PV size, there is a significant interaction term of PV size and wind turbine rotor swept area, $x_{1}$, $\mathrm{x}_{2}$. Besides, the quadratic effects of $x_{2}$ and $x_{3}$ are statistically significant $(P<0.05)$. It should be noticed that only the second factor affects the cost negatively while the others affect it positively.Design Expert 7.1 RSM result indicates that the stationary point (optimum) of the fitted response surface, $X_{0}=\left(x_{1}, x_{2}, x_{3}\right)$, is $(-0.21$, $0.24,0.096)$ as coded variable and $(3.95,29.4,31.92)$ as the real value yielding a predicted mean response of $Y_{0}=\$ 37,033.9\left(C_{T}\right)$, a minimum in the experimental region. Because the battery's efficiency is considered as $85 \%$, a $37.55 \mathrm{~kW} \mathrm{~h}$ battery should be used in the hybrid system. When we run the simulation model at the optimum point the total energy met by the auxiliary energy source in $175,200 \mathrm{~h}$ is obtained as $2,043.85 \mathrm{~kW} \mathrm{~h}$, which means a shortage cost of $\$ 1,021.925$. This shortage cost can be interpreted as small portion in the whole hybrid system cost. Fig. 7, illustrates the 3D surface graph of cost response at the optimum battery capacity, $31.92 \mathrm{~kW} \mathrm{~h}$, as a function of two factors, PV size, $x_{1}$, and wind turbine rotor swept area, $x_{2}$.

From this figure, while one battery capacity is fixed at $31.92 \mathrm{~kW} \mathrm{~h}$, the trade-offs between PV size and wind turbine rotor swept area can be seen easily. And also, by the figure, the coded optimum values can be seen around the minimum point of the convex shape.

\section{Loss of load probability and autonomy analysis}

In this paper, the performance of the optimum point of the hybird system is confirmed in terms of LLP and autonomy analysis on

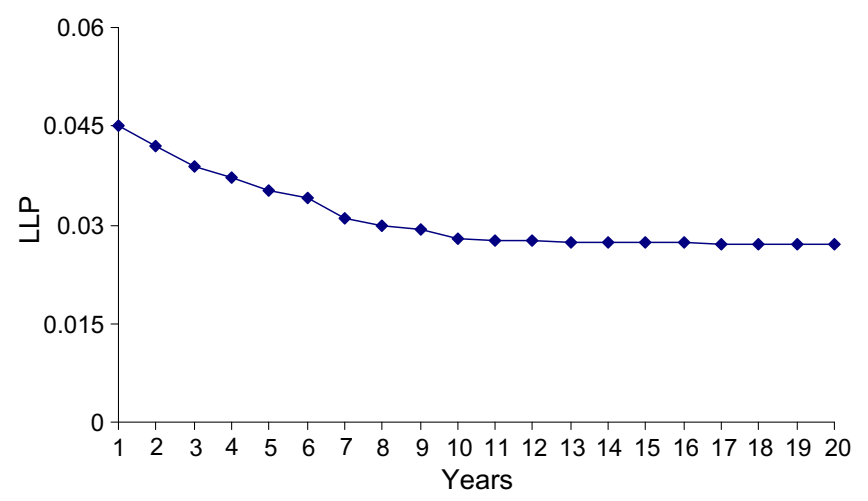

Fig. 8. Yearly LLP values. 


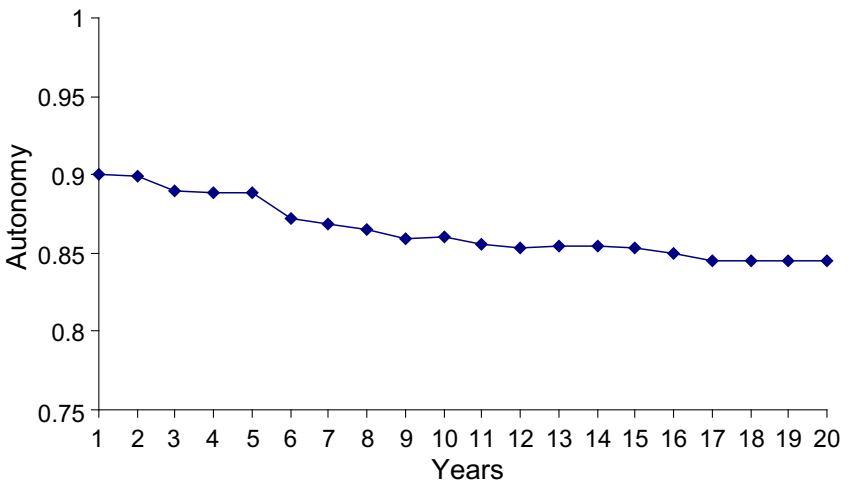

Fig. 9. Yearly autonomy values.

an hourly basis. LLP is defined as, Eq. (9). Here $S_{j}$ is the total amount of the electricity energy shortage because of not meeting the demand during year $j$ and $C_{j}$ is the total amount of the electricity energy consumption by GSM base station during year $j$, and $n$ is the simulation time period, as hour. At the end of the every $n$ year, the LLP is calculated according to Eq. (9). Autonomy is one minus the ratio of the total number of hours in which loss-of-load occurs to the total hours of operation and is given by Eq. (10) [31].

As a result, at the optimum point, the LLP and autonomy curves obtained from the hybrid system simulation are given in Figs. 8 and 9, respectively. According to the figures, the LLP value changes between 0.045 and 0.027 and autonomy value changes between 0.9 and 0.845 which can be seen reasonable. LLP and autonomy values reach their steady state values after a while. If we chose the warm-up period as a longer time period, LLP would reach its steady state value faster than the Figs. 8 and 9. Here, because the unit cost of auxiliary energy is high, the LLP is obtained as small values. If it was taken a smaller value than 0.5 , the optimum points so, the LLP would change. Consequently, the optimum sizes which we obtained by the RSM is reasonable and can be used for the break-even analysis.

$\mathrm{LLP}=\frac{\sum_{j=0}^{n} S_{j}}{\sum_{j=0}^{n} C_{j}}$
$A=1-\frac{D_{\mathrm{LOL}}}{D_{\mathrm{TOT}}}$

\section{Break-even analysis}

A break-even distance analysis is performed for each autonomous hybrid energy system and extension of transmission line. This analysis determines how far the site of the stand-alone alternative energy system should be from the existing utility line so that the system is cost effective (breaks even) when compared to using conventional transmission line. For the cost analysis, net present value (NPV) method is used. Below, each case is explained in details.

\subsection{Autonomous hybrid PV/wind energy system: case $A$}

Optimum hybrid energy system cost has been calculated in simulation above as $\$ 37,033.9$. In calculating the cost of the hybrid energy system, a 20 year lifetime is assumed. In addition, in the 5th, 10 th, and the 15th years, battery replacement cost and in the 10th year, inverter replacement cost will be added to this total cost. The renewal costs of battery and inverter are estimated as $\$ 6759$

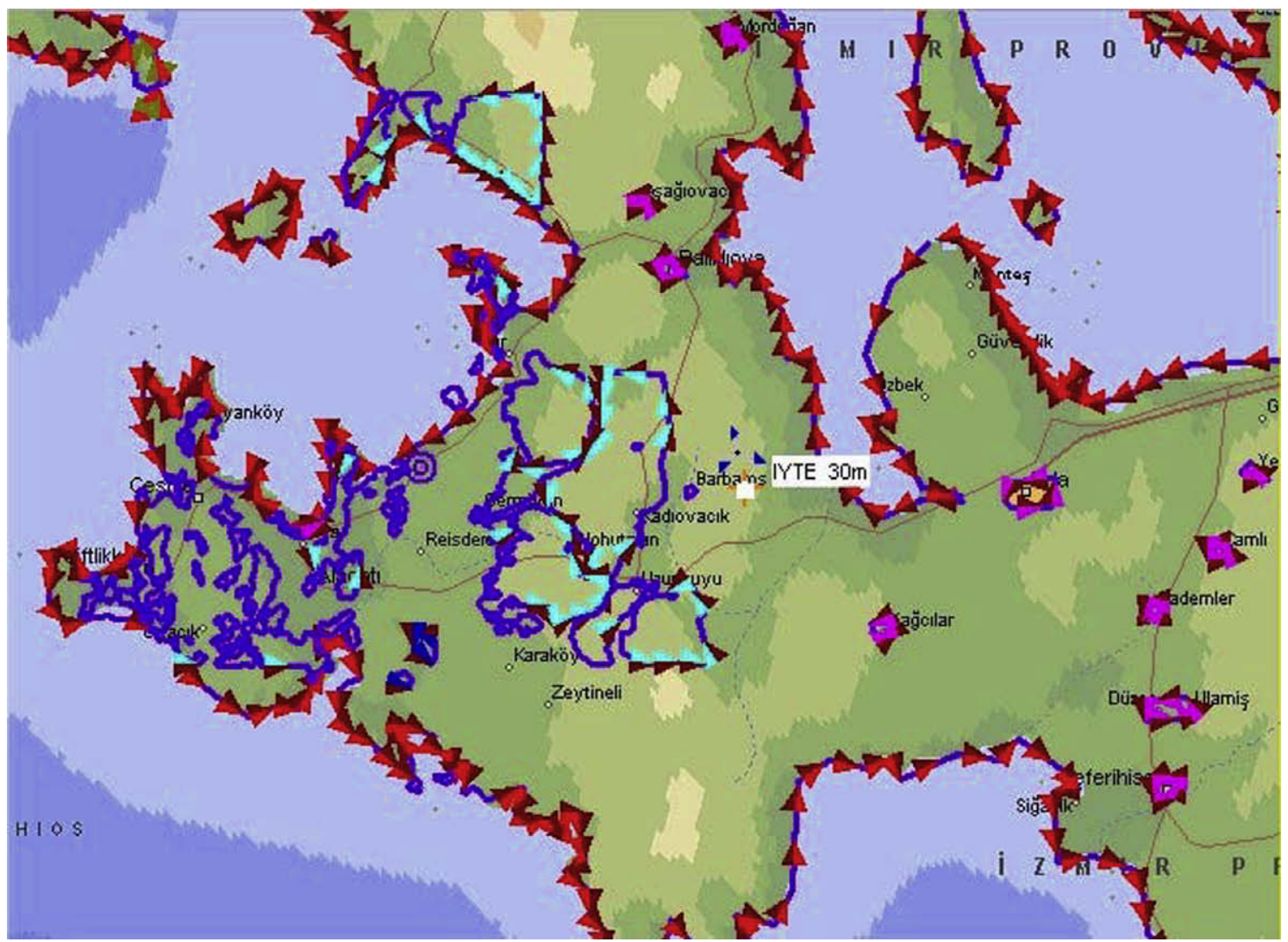

Fig. 10. Location of the site. 
$(180 \$ / \mathrm{kWh} * 37.55 \mathrm{kWh})$ and $\$ 5350$, respectively. The detailed cost of the hybrid system is illustrated in Table 8 .

\subsection{Extension of transmission line: case $B$}

The other energy supply scenario is to extend the transmission line which is $x$ meters away from the location where the hybrid system is assumed to be installed. The location where the GSM base station is installed and the hybrid system is assumed to be installed is right by the Aegean Sea and has a hilly topography. It has several hills with $15-25 \%$ incline. These hills are covered with typically Mediterranean bushes. Soil depth is very low and not suitable for vegetation. Fig. 10 shows the site on Izmir map.

The total cost, for this scenario, changes according to the length of the transmission line. This cost is sum of operation cost and investment cost [32]. Operation costs of the grid system are the electricity consumption fee and the maintenance costs. Sum of the transformer and transformer pile, power panel, separator, project development costs are considered as the fixed cost whereas the pile, conductive wire, insulator, grounding, and labor costs are considered as the variable cost in the initial investment cost. The fixed cost is calculated for $50 \mathrm{kV}$ A power demand in the case study. The cost values are obtained from the Turkish Chamber of Electrical Engineers and Turkish State of Electric Distribution. Grid line components and their costs are given in Table 7.

Total cost of the extension of transmission line case is yielded as

Total Cost of Extension Transmission Line

$$
=\text { Investment Cost }+ \text { Operation Cost }
$$

The total operation cost of the extended transmission line is given by Eq. (12):

$$
\begin{aligned}
\text { Total Operation Cost }= & \sum \text { Maintenance Cost } \\
& +\sum \text { Electricity Consumption Fee } \\
& - \text { Salvage }
\end{aligned}
$$

Consequently, from Table 7, the total cost $\left(T C_{t}\right)$ of extended trans-

\begin{tabular}{|c|c|c|}
\hline Components & $\begin{array}{l}\text { Unit } \\
\text { used }\end{array}$ & $\begin{array}{l}\text { Unit cost } \\
(\$)\end{array}$ \\
\hline \multicolumn{3}{|l|}{ Variable costs } \\
\hline \multicolumn{3}{|l|}{ Concrete pile } \\
\hline Pile 8-12 (2170 kg) & Item & 298.74 \\
\hline Pile installation & Item & 572.88 \\
\hline Pile transportation & Pile-m & 0.05 \\
\hline Wire $(110$ kg/km) & M & 0.3751 \\
\hline \multicolumn{3}{|l|}{ Concrete sleeper } \\
\hline Sleeper T 27/260 (100 kg) & Item & 19.63 \\
\hline Sleeper installation & Item & 20.05 \\
\hline Sleeper transportation & Pile-m & 0.002 \\
\hline Support insulator & Item & 19.11 \\
\hline \multicolumn{3}{|l|}{ Fixed costs } \\
\hline Pile $14-12(2790 \mathrm{~kg})+$ installation & 1 item & 1011 \\
\hline Transformer platform PL-250 (700 kg) & 1 item & 206.28 \\
\hline Current transformer $75 / 5 \mathrm{~A}, \mathrm{Cl}: 0.5$ & 3 item & 17 \\
\hline OG fuse $36 \mathrm{kV}, 2-20 \mathrm{~A}$ & 6 item & 176.4 \\
\hline Fuse separator $36 \mathrm{kV}-630 \mathrm{~A}$ & 1 item & 525 \\
\hline Ground separator $36 \mathrm{kV}-630 \mathrm{~A}$ & 1 item & 460 \\
\hline Power panel & 1 item & 920 \\
\hline Electric meter $220 / 380 \mathrm{~V}$ & 1 item & 300 \\
\hline $\begin{array}{l}\text { Circuit breaker } 3 \times 80 \mathrm{~A} \text { compact (thermic-magnetic- } \\
\text { automatic) }\end{array}$ & 1 item & 29.7 \\
\hline Distributor transformer $31.5 \mathrm{kV}, 50 \mathrm{kVA}$ & 1 item & 2912 \\
\hline Others & & 1454.26 \\
\hline
\end{tabular}
mission line for the mentioned location is obtained as Eq. (13).

\section{Table 7}

Grid line system components and their costs.
The variable cost function of the $T C_{t}\left(0.0007 x^{2}+12.483 x\right)$ is obtained using regression analysis by calculating for different distance options. The function's $R^{2}$ value is obtained as 1 which can be accepted reasonable. Here, $x$ is the transmission line length as meter. In other words, it is the distance from the network where the hybrid system is installed. Since, the cost function is nonlinear, when the distance from the transmission line of the location increases, then the extension cost of the transmission line increases as polynomial.

$$
\begin{aligned}
T C= & \left(0.0007 x^{2}+12.483 x+8011.64+\left(0 . 1 ^ { * } \left(0.0007 x^{2}+12.483 x\right.\right.\right. \\
& \left.+8011.64))+40^{*} 900-5000\right)
\end{aligned}
$$

In Eq. (13), 8011.64 is the fixed cost of the extension of the transmission line which is calculated from the Table 7 of the fixed cost column. The economical life of the extended transmission line is considered as 40 years. And, the estimated annual maintenance cost is assumed as $10 \%$ of the initial investment cost of the transmission line which is " $0.1 *\left(0.0007 x^{2}+12.483 x+8011.64\right)$ " part in Eq. (13). In addition, expected annual electricity consumption costs are $\$ 900$ per year. And the total salvage value for grid connected system is expected as $\$ 5000$.

\subsection{Break-even analysis results}

To be able to compare the life cycle cost values of the both, autonomous hybrid energy system and extended transmission line, the economical life of the systems are equalized to 40 years. Therefore, the hybrid system is renewed once after 20 years of operation. Detailed comparison of the autonomous hybrid energy system and extended transmission line costs for $4000 \mathrm{~m}$ distance between national electricity network and the location where the hybrid system is assumed to be installed is seen in Table 8 .

Here, the location where the hybrid system is assumed to be installed is around $4000 \mathrm{~m}$ far away from the electricity network. Therefore, as seen in Table 8, the extension of the transmission line is calculated as $4000 \mathrm{~m}$. and obtained as $15.66 \%$ greater than the hybrid energy system. So, here extension of the transmission line is more economic than the hybrid energy system. In order to find out the optimum extended transmission line distance, where the hybrid energy system becomes economic, break-even analysis is performed. In the break-even analysis, decision variable is the distance between GSM base station location where the hybrid energy system is assumed to be installed and the national electricity network. This distance is found by equating the costs of above mentioned two cases. The intersection point of is found to be $4817 \mathrm{~m}$. If distance between the national electricity network and the GSM base station location where the hybrid system is assumed to be installed is longer than $4817 \mathrm{~m}$, installation of the hybrid energy system becomes more economical than the transmission line. The graphic form of this result is shown in Fig. 11.

\begin{tabular}{|c|c|c|}
\hline Items & $\begin{array}{l}\text { Case A (US\$) } \\
\text { hybrid system }\end{array}$ & $\begin{array}{l}\text { Case B (US\$) ( } 4000 \mathrm{~m} \text { distance from } \\
\text { national electricity network) }\end{array}$ \\
\hline Initial investment & $2 \times 37,033.9$ & $69,143.64$ \\
\hline Maintenance & $\begin{array}{l}\text { Included in initial } \\
\text { investment cost }\end{array}$ & $6,914.364$ \\
\hline Battery renewal & $6 \times 6,759$ & - \\
\hline Inverter renewal & $2 \times 5,350$ & - \\
\hline Annual net payment & - & $40 \times 900$ \\
\hline Salvage value & $2 \times 750$ & 5,000 \\
\hline Total & $\$ 123,821.8$ & $\$ 107,058.004$ \\
\hline
\end{tabular}

In this study, when comparing the two alternative systems, intangible effects e.g., the positive effects of the hybrid energy system to the environment, clean, renewable etc., are not considered.

Table 8

Comparison of alternative investment cases for 40-year life. 


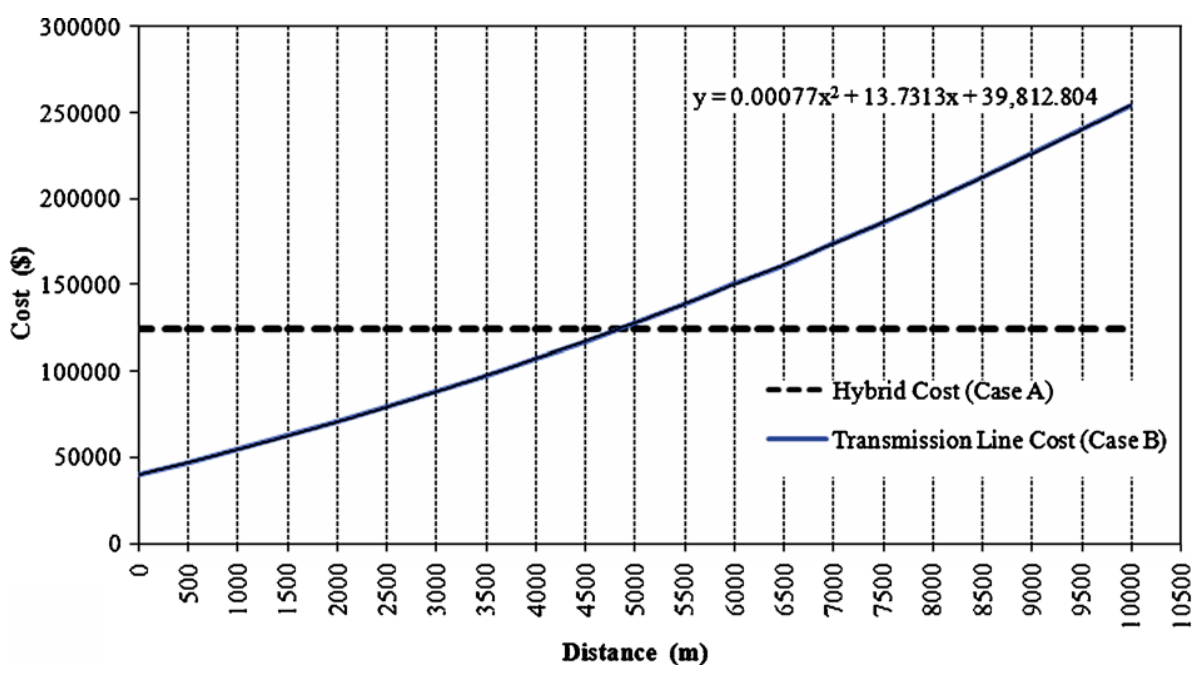

Fig. 11. Break-even analysis of hybrid energy system and grid line cost.

Therefore, $15.66 \%$ expensiveness of the hybrid energy system can be ignored and this system can be chosen as the electricity supplier for the GSM.

\section{Conclusions}

In this study, size of a PV/wind hybrid energy conversion system with battery storage is optimized using Box-Behnken design and RSM based on an hourly operating cost. Then, break-even analysis is completed to be able to decide which investment is beneficial for the area. First of all, a simulation model for conducting a detailed hybrid energy system analysis and size level evaluation is described. The simulation model is completed based on the historical hourly mean solar radiation and wind speed data for the period of 2001-2003 recorded at the meteorological station, Izmir Institute of Technology Campus Area, Urla, Turkey. Second, the regression metamodel of the hybrid energy system is obtained from the outputs of this simulation model using Box-Behnken design. Finally, the classical optimization technique known as RSM is used to optimize this regression metamodel. As a result, the optimum PV area, wind turbine rotor swept area, and battery capacity are obtained to be $3.95 \mathrm{~m}^{2}, 29.4 \mathrm{~m}^{2}, 31.92 \mathrm{~kW} \mathrm{~h}$, respectively. These results led to $\$ 37,033.9$ hybrid energy system cost, including the shortage energy cost met by the auxiliary energy. The optimum result obtained by RSM is confirmed using LLP and autonomy analysis. In the second part of the study, other alternative way of an electricity production which is the extension of the transmission grid line is considered. The mathematical cost formulation of the transmission grid line is obtained as Eq. (13). And then, break-even analysis is done as seen in Fig. 11. As a result, the break-even point is obtained as $4817 \mathrm{~m}$. It defines that after this distance using a hybrid system is more economic than the grid line system. However, since the cost difference between the two system is low, $15.66 \%$, and the hybrid energy system is renewable and environment friendly, this system still can be used for energy supplier of the GSM base station.

The methodology described in this study provides an important and systematic approach for design, analysis of hybrid energy systems and choosing the best energy system for the remote areas. The optimization ability is especially helpful if the simulation of a system is very large and costly, precluding exploration of all but a few input-parameter combinations. The development of the metamodel makes possible, so better understanding of the true relationship between input variables such as the PV size, wind turbine rotor swept area, and battery capacity, and output variables such as the hybrid energy system cost. Besides, evaluation of a hybrid energy system and extension of the transmission line via the break-even analysis has shown a way to be able to decide on the profitable two alternative systems.

\section{References}

[1] Borowy BS, Salameh ZM. Optimum photovoltaic array size for a hybrid windPV system. IEEE Trans Energy Convers 1994;9(3):482-8.

[2] Borowy BS, Salameh ZM. Methodology for optimally sizing the combination of a battery bank and PV array in a wind-PV hybrid system. IEEE Trans Energy Convers 1996;11(2):367-75.

[3] Markvart T. Sizing of hybrid photovoltaic-wind energy systems. Solar Energy 1996;57(4):277-81.

[4] Bagul AD, Salameh ZM, Borowy B. Sizing of stand-alone hybrid wind-PV system using a three event probability density approximation. Solar Energy 1996;56(4):323-35.

[5] Celik AN. Optimisation and techno-economic analysis of autonomous photovoltaic-wind hybrid energy systems in comparison to single photovoltaic and wind systems. Energy Convers Manage 2002;43(18):2453-68.

[6] Morgan TR, Marshall RH, Brinkworth BJ. ARES - a refined simulation programme for the sizing and optimization of autonomous hybrid energy systems. Solar Energy 1997:59(4):205-15.

[7] Yang HX, Burnett J, Lu L. Weather data and probability analysis of hybrid photovoltaic-wind power generation systems in Hong Kong. Renew Energy 2003;28(11):1813-24.

[8] Ashok S. Optimised model for community-based hybrid energy system. Renew Energy 2007;32(7):1155-64.

[9] Bakos GC, Soursos M. Technoeconomic assessment of a stand-alone PV/hybrid installation for low-cost electrification of a tourist resort in Greece. Appl Energy 2002;73(2):183-93.

[10] Yang H, Zhou W, Lou C. Optimal design and techno-economic analysis of a hybrid solar-wind power generation system. Appl Energy 2008;86(2):163-9.

[11] Protegeropoulos C, Brinkworth BJ, Marshall RH. Sizing and techno-economical optimization for hybrid solar photovoltaic/wind power systems with battery storage. Int J Energy Res 1997;21(6):465-79.

[12] Seeling-Hochmuth GC. A combined optimization concept for the design and operation strategy of hybrid-PV energy systems. Solar Energy 1997;61(2):77-87.

[13] Kellogg W, Nehrir MH, Venkataramanan G, Gerez V. Optimal unit sizing for a hybrid wind/photovoltaic generating system. Electric Power Syst Res 1996;39(1):35-8.

[14] Eke R, Kara O, Ulgen K. Optimization of a wind/PV hybrid power generation system. Int J Green Energy 2005;2(1):57-63.

[15] Law AM, Kelton WD. Simulation modeling and analysis. 3rd ed. McGraw-Hill; 2000.

[16] Kleijnen JPC, Sargent RG. A methodology for fitting and validating metamodels in simulation. Euro J Oper Res 2000;120(1):14-29.

[17] Kleijnen JPC. Statistical tools for simulation practitioners. 1st ed. New York: Marcel Dekker; 1987

[18] Friedman LW. The simulation metamodel. 1st ed. Netherlands: Kluwer; 1996.

[19] Myers RH, Montgomery DC. Response surface methodology: process and product optimization using designed experiments. 1st ed. New York: John Wiley \& Sons; 1995.

[20] Box GEP, Draper NR. Empirical model-building and response surfaces. 1st ed. New York: John Wiley \& Sons; 1987. 
[21] Field AP. Discovering statistics using SPSS. 2nd ed. London, UK: Sage; 2005.

[22] Kleijnen JPC. Verification and validation of simulation models. Euro J Oper Res 1995;82(1):145-62.

[23] Panis RP, Myers RH, Houck EC. Combining regression diagnostics with simulation metamodels. Euro J Oper Res 1994;73(1):85-94.

[24] Kelton WD, Sadowski RP, Sturrock DT. Simulation with arena. 3rd ed. New York: McGraw-Hill; 2004.

[25] Ekren O. Optimization of a hybrid combination of a photovoltaic system and a wind energy conversion system. MS thesis, Department of Mechanical Engineering, Izmir Institute of Technology; 2003.

[26] AWS Scientific. Inc. Wind resource assessment handbook. NREL/SR-44022223, National Renewable Energy Laboratory: 1997.

[27] Muselli M, Notton G, Louche A. Design of hybrid photovoltaic power generator with optimization of energy management. Solar Energy 1999;65(3):143-57.
[28] Kemmoku Y, Egami T, Hiramatsu M, Miyazaki Y, Araki K, Ekins-Daukes NJ, Sakakibara T. Modelling of module temperature of a concentrator PV system. In: Proceedings of the 19th European photovoltaic solar energy conference; 2004. p. 2568-71.

[29] Box GEP, Hunter WG, Hunter JS. Statistics for experimenters. 1st ed. New York: Wiley; 1978.

[30] Montgomery DC. Design and analysis of experiments. 3rd ed. New York: Wiley; 1991

[31] Celik AN. Techno-economic analysis of autonomous PV-wind hybrid energy systems using different sizing methods. Energy Convers Manage 2003;44(12):1951-68.

[32] Branson R, Nadimuthu G. Theory and problems of operation research. McGraw-Hill: New York; 1997. 